\title{
Formation of Subtropical Mode Water in a High-Resolution Ocean Simulation of the Kuroshio Extension Region
}

\author{
Luc Rainville $^{\mathrm{a} *}$, Steven R. Jayne ${ }^{\mathrm{a}}$, Julie L. McClean ${ }^{\mathrm{b}}$, and Mathew E. Maltrud ${ }^{\mathrm{c}}$ \\ a Physical Oceanography Dept., Woods Hole Oceanographic Institution, MS \#21, \\ Woods Hole, MA 02543-1541 \\ bscripps Institution of Oceanography, 9500 Gilman Dr., La Jolla, CA, 92093-0230 \\ ${ }^{\mathrm{c}}$ Los Alamos National Laboratory, P.O. Box 1663 Los Alamos, NM 87545
}

\section{Accepted at Ocean Modelling, 9 March 2007}

A high-resolution numerical model is used to examine the formation and variability of the North Pacific Subtropical Mode Water (STMW) over a 3-year period. The STMW distribution is found to be highly variable in both space and time, a characteristic often unexplored because of sparse observations or the use of coarse resolution simulations. Its distribution is highly dependent on eddies, and where it was renewed during the previous winter. Although the potential vorticity fluxes associated with down-front winds can be of the same order of magnitude or even greater than the diabatic ones due to air-sea temperature differences, the latter dominate the potential vorticity budget on regional and larger scales. Air-sea fluxes, however, are dominated by a few strong wind events, emphasizing the importance of short time scales in the formation of mode waters. In the Kuroshio Extension region, both advection and mixing play important roles to remove the STMW from the formation region.

\section{Introduction}

North Pacific Subtropical Mode Water (STMW) is formed south of the Kuroshio Extension during winter convection driven by large atmospheric heat fluxes (Masuzawa, 1969; Bingham, 1992; Suga and Hanawa, 1995a). As substantial reservoirs of heat, mode waters are believed to play a major role in climate (Bates et al., 2002 ; Joyce et al., 2000). The volume and properties of mode waters have been observed to vary significantly on seasonal and inter-annual time scales (Kwon and Riser, 2004). To first order, the formation rate and properties of the STMW are thought to be mainly dependent on wintertime atmospheric heat fluxes (Suga and Hanawa, 1995b). More recently, the oceanic circulation has been shown to play an important role not only in spreading but also in regulating the formation of STMW. Qiu and Chen (2006) found the decadal variability of the STMW to be related to the dynamic state of the Kuroshio Extension, as the large mesoscale variability associated with an unstable Kuroshio reduces the formation of STMW. Studies of the STMW have focused on the average circulation and low-frequency correlations due to limited observations.

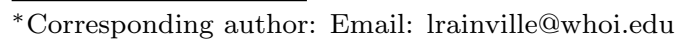

Numerical simulations offer a unique look at the time and space variability of the STMW. In this paper, we investigate the role of the atmosphere, the ocean circulation, and their interaction in the formation and evolution of STMW. The model and its representation of the Kuroshio Extension are described in section 2. Finding good metrics for evaluating the performance of numerical models is a challenging task. One goal of the present study is to focus on an important physical process, namely the formation and erosion of STMW, to understand how the model performs: in what ways it is successful and where it fails. Section 3 examines the representation of STMW in the model, particularly where it is formed and how it evolves over a 3-year period. Changes in the properties (temperature, potential vorticity, density) of the STMW layer are discussed and we estimate the total volume of STMW, how much is formed, exported and eroded.

The processes responsible for the formation and erosion of STMW are discussed in more detail in section 4, in which the dominant terms in the mass budget are evaluated for a control volume defined by the isopycnals bounding the STMW. The variability in the air-sea fluxes from year to year, due to both atmospheric variability (wind 
events) and feedback from the state of the ocean, is directly reflected in the quantity of mode water formed. In section 5, we investigate the relative importance of the frictional and diabatic potential vorticity fluxes in the potential vorticity budget. The cross-frontal advection of buoyancy by the Ekman surface transport has been suggested to be an important component of the potential vorticity budget of a frontal region (Thomas and Lee, 2005). Although local values of frictional (Ekman) potential vorticity flux are of the same order, or even greater, than the diabatic (air-sea) ones, the frictional term does not appear to play a major role on a regional budget of STMW.

\section{The Kuroshio in the POP model}

\subsection{Model description}

The Parallel Ocean Program (Smith et al., 1992; Dukowicz et al., 1993; Dukowicz and Smith, 1994 ) is a 3 -dimensional, z-level, primitive equation general circulation ocean model with an implicit free surface. Details of the model formulation can be found at http://climate.acl.lanl.gov. The output analyzed in this study came from a multi-decadal global $1 / 10^{\circ}$, 40-level global POP simulation (Maltrud and McClean, 2005; McClean et al., 2006) configured on a displaced North Pole grid $(3600 \times 2400 \times 40$ points $)$ with realistic topography (Sandwell and Smith, IBCAO and BEDMAP). It includes a K-Profile Parameterization (KPP) mixed layer (Large et al., 1994). It was forced with surface boundary conditions primarily from the National Center for Environmental Prediction (NCEP)-National Center for Atmospheric Research (NCAR) reanalysis data (Doney et al., 2002) for the period 1979-2003. A combination of daily and monthly fields was employed to estimate the surface momentum, heat, and freshwater fluxes using bulk formulae of Large et al. (1997). Daily forcing fields (6-hourly fields averaged to one day) of wind stress, air temperature, air density and specific humidity were derived from the NCEP-NCAR reanalysis data (Kalnay et al., 1996). Monthly downward shortwave radiation and cloud fraction came from the International Satellite Cloud Climatology Project (ISCCP) and Rossow and Schiffer (1991), respectively. Monthly mean precipitation data was taken from the Microwave Sounding Unit (MSU) and Xie-Arkin climatology (Xie and Arkin, 1997). The model was initialized from the Navy's Modular Ocean Data Assimilation System (MODAS)
1/8 January climatology (Fox et al., 2002) outside of the Arctic and the University of Washington's Polar Hydrography winter climatology in the Arctic. Note that besides the atmospheric forcing being derived from the re-analyses of observations, the model does not assimilate data. More information about the model can be found at http://www.oc.nps.navy.mil/navypop/. The model was spun-up for two decades, and daily averages of the model output were archived for the Kuroshio Extension region (roughly the domain shown in Fig. 1a) for the following 3-year period, from 1 January 1998 to 31 December 2000. In this study, we define two regions for budget and averaged quantities: a larger Region A, encompassing the whole Kuroshio current system after it exits the East China Sea, and Region B, a smaller region away from topography in the eastern portion of the extracted domain. Both regions are shown in Fig. 1a,c.

\subsection{Comparison with altimetry}

Geostrophic currents at the ocean surface are directly related to the horizontal gradient of seasurface height (SSH), $\eta(x, y)$, by the geostrophic relations (Gill, 1982). The averaged SSH from the 3 years (1998-2000) of archived daily model output is shown in Fig. 1a. Kuroshio meanders are still apparent in this relatively short time average. A definite recirculation on the southern side of the Kuroshio is seen, but no northern recirculation is apparent in the surface currents.

We compare the model SSH with that from altimetry (Fig. 1b) obtained from the Aviso/Altimetry project. Maps of SSH are obtained using the objective mapping method detailed in Ducet et al. (2000), merging SSH anomaly measurements recorded from multiple satellite altimeters and adding the Rio05 absolute dynamical topography (Rio and Hernandez, $2004)^{2}$. The averaged absolute SSH from altimetry from Jan 1998 to Dec 2000, and the corresponding variance (Fig. 1d) show a smoother Kuroshio (in part due to the large spatial scale of the Aviso objective mapping, about $200 \mathrm{~km}$ at these latitudes) and a weaker surface recirculation than seen in the model.

In general, the Kuroshio in the period 19982000 exhibited greater variability than in recent years (2002-2004) (Qiu and Chen, 2005). Al-

\footnotetext{
${ }^{2}$ The altimeter products were produced by Ssalto/Duacs and distributed by Aviso, with support from CNES. Rio05 was produced by CLS Space Oceanography Division
} 

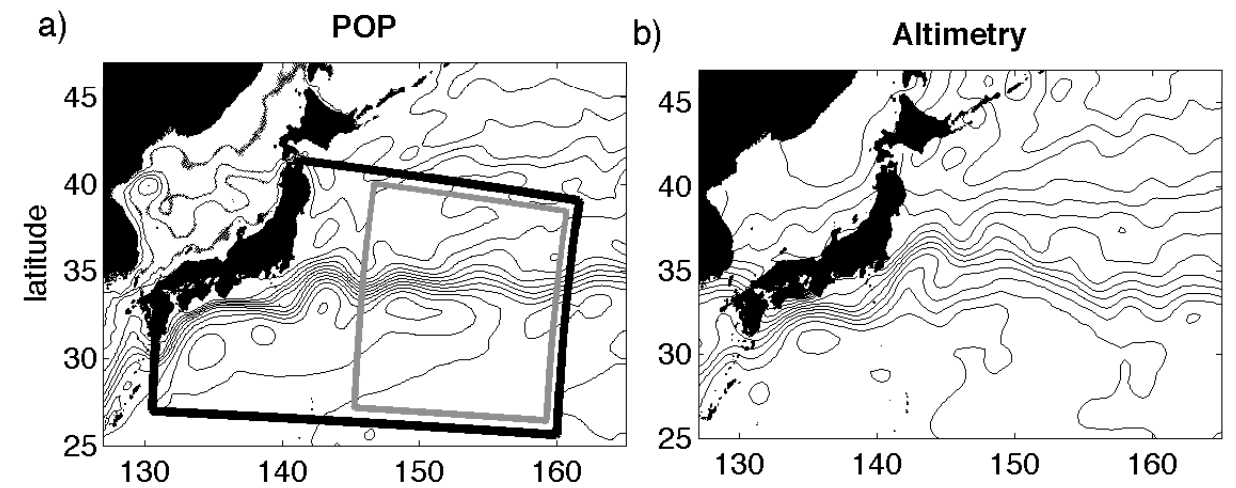

c)

d)
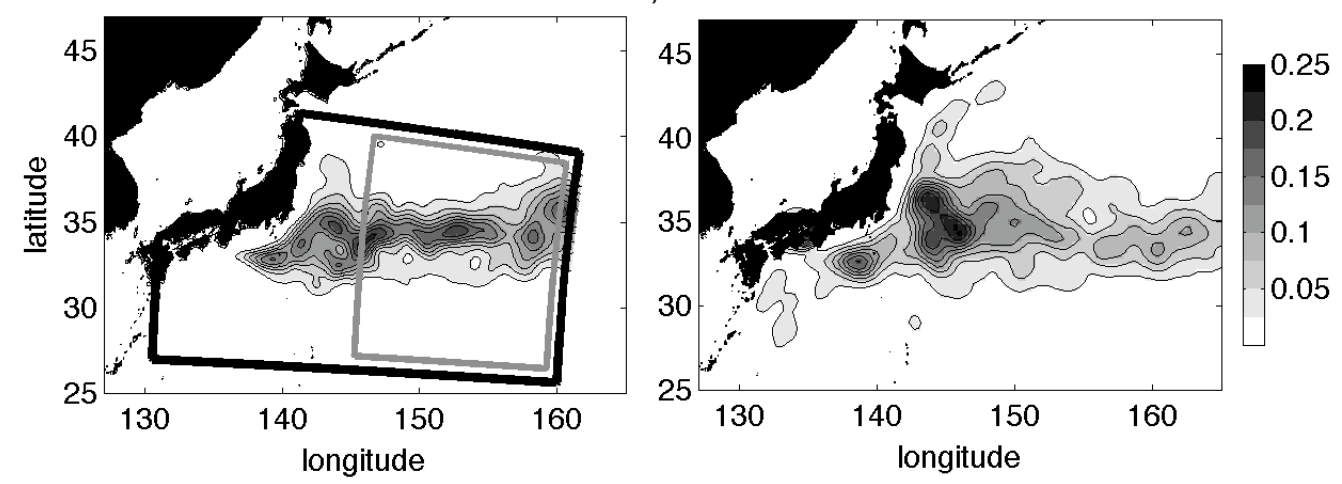

Figure 1. (a) Sea-surface height from the POP model, averaged over 3 years (1998-2000). (b) Corresponding average of the observations of SSH from altimetry. (c) SSH variance in POP and (d) from altimetry from 1998 to 2000. The contour intervals are $0.1 \mathrm{~m}$ in $(\mathrm{a}, \mathrm{b})$ and $0.025 \mathrm{~m}^{2}$ in $(\mathrm{c}, \mathrm{d})$. The boundaries of the regions referred as Region A and Region B are shown in black and gray, respectively.

though oceanographic data are not assimilated in the POP model (only the atmospheric forcing is derived from observations), it seems that the variability of the Kuroshio in POP is also high during the period considered here. In both the model and altimetry maps, the meanders of the Kuroshio during the years 1998-2000 are never stationary for extended periods of time. The mean variance over the Region A (roughly $135^{\circ} \mathrm{E}$ to $160^{\circ} \mathrm{E}, 30^{\circ} \mathrm{N}$ to $40^{\circ} \mathrm{E}$ ) is similar: 0.045 $\mathrm{m}^{2}$ in the model and $0.051 \mathrm{~m}^{2}$ in the altimetry maps. However, almost all the eddy variance of the model appears to be due to instabilities of the jet, compared to a relatively broader distribution in the altimetry data, a sign that some open-ocean processes generating eddies or other instability processes are probably missing in the model.

\subsection{A section across the Kuroshio}

The Kuroshio Extension System Study (KESS), a major 2-year observational program of the Kuroshio current, was started in 2004. Its goal is to further our understanding of the dynamics of the western boundary current and its associated recirculation gyres. During the first of the KESS cruises, a Conductivity-TemperatureDepth (CTD) section was collected along a ground track of TOPEX/Poseidon that intersected the Kuroshio around $146^{\circ} \mathrm{E}$, and was found to be relatively free of other mesoscale features (Qiu et al., 2006). To compare the model results with direct observations, a weekly average of the simulation in the same season was chosen when the Kuroshio Extension System showed a similar meandering state.

The potential density, potential vorticity, and eastward velocities from the model and those 
measured in May 2004 across the Kuroshio are shown in Fig. 2. The observed fields are obtained by a composite of all the CTD stations collected during KESS along that particular line, the velocity section shown in Fig. $2 f$ is derived from a smooth objective map of the shipboard Acoustic Doppler Current Profiler (ADCP) data. The planetary potential vorticity, $Q$, is defined as

$$
Q \equiv-\frac{f}{\rho} \frac{\partial \sigma_{\theta}}{\partial z},
$$

where $f$ is the inertial frequency, $\rho$ the density, and $\sigma_{\theta}$ the potential density. Corresponding fields in the POP model, along the same section but averaged over the last week of May 1999, are shown in Fig. 2. Note that the particular location of the core of the Kuroshio is not important, since it is stochastically meandering.

The model compares relatively well with the hydrographic observations. The model fields are smoother, primarily due to limited vertical resolution of the model: there are 9 vertical levels between the surface and $100 \mathrm{~m}, 5$ between 100 and $200 \mathrm{~m}$, and 6 between 200 and $600 \mathrm{~m}$. In both cases, the potential vorticity minimum $\left(Q<2 \times 10^{-10} \mathrm{~m}^{-1} \mathrm{~s}^{-1}\right)$ on the south side of the Kuroshio extends close to the core of the current. The magnitudes of the variables are similar, and the steepness of the Kuroshio front is comparable. The maximum eastward speed in the model in the model is $0.6 \mathrm{~m} \mathrm{~s}^{-1}$, compared to $1.1 \mathrm{~m}$ $\mathrm{s}^{-1}$ in the observations. While the maximum potential vorticity in this section in the model is comparable to that of the observations (36 and $47 \times 10^{-10} \mathrm{~m}^{-1} \mathrm{~s}^{-1}$, respectively), the minimum potential vorticity, found in the STMW layer, is not nearly as small in the model $\left(0.7 \times 10^{-10}\right.$ $\mathrm{m}^{-1} \mathrm{~s}^{-1}$ relative to $0.2 \times 10^{-10} \mathrm{~m}^{-1} \mathrm{~s}^{-1}$ in the observations. Despite these differences, the representation of the Kuroshio Extension region in the POP model appears to be realistic: distinct water masses are present at the right densities, an unstable meandering jet is well resolved, and the average kinetic energy of the region is of the right order of magnitude.

\section{Subtropical mode water}

\subsection{Definition}

The subtropical mode water (STMW) is defined here as a potential vorticity minimum of $Q<2 \times 10^{-10} \mathrm{~m}^{-1} \mathrm{~s}^{-1}$ with a potential density range of 25.0 to $25.5 \sigma_{\theta}$. The density condition, necessary to exclude the unstratified (low- potential vorticity) surface mixed layer and other water masses, is equivalent to choosing a temperature range between $16^{\circ} \mathrm{C}$ and $19^{\circ} \mathrm{C}$. The density criterion is rather wide, allowing for variations of the properties of the STMW from year to year. The average STMW temperature is between $17^{\circ} \mathrm{C}$ and $18^{\circ} \mathrm{C}$. The STMW is evident in both the model and observations (Fig. 2). This definition of STMW, derived from the KESS ( Qiu et al., 2006) and historical observations, is adequate for the more qualitative discussion of this section. Later in this paper, we consider the density layer that includes all of the STMW to calculate volume and potential vorticity budgets.

In contrast to the classic picture of mode water distribution obtained from large scale surveys or climatology, a map of the STMW thickness on any given day shows large spatial variability (Fig. 3a). Perhaps not surprisingly, eddies and recirculations play an important role in the distribution of mode water. The cyclonic eddy located at $32^{\circ} \mathrm{N} 143^{\circ} \mathrm{E}$ does not contain STMW, whereas the anticyclonic recirculation around $31^{\circ} \mathrm{N} 136^{\circ} \mathrm{E}$ traps more intense STMW. Using in-situ profiling floats deployed in 2004, Qiu et al. (2006) inferred a highly variable STMW distribution, with the greatest thicknesses occurring in anticyclonic recirculations under the crests of the meanders, as we find in the model. As discussed below, the spatial variability in formation (and erosion) of STMW also affects its distribution.

The model provides a detailed look at the seasonal evolution of the STMW. For example, monthly averaged distributions of STMW based on the POP model are shown in Fig. 4 for every other month of 1998. A large volume of STMW is formed just south of the Kuroshio between February and April, just south of each crest of the meandering current, and slowly erodes during the following summer and fall. Averaged over a long enough period of time, for example over 3 years (Fig. 3b) the distribution of STMW from the model resembles the classic figures of Worthington (1959) and Masuzawa (1969), showing smooth distributions of $18^{\circ} \mathrm{C}$ water south of the Gulf Stream or Kuroshio. However, at any given time the distribution is quite non-uniform.

\subsection{STMW time series}

During the winter, the deep mixed layer penetrates into the STMW layer and renews the potential vorticity minimum (Fig. 5). This leads to a sharp increase in the volume of the STMW. Af- 

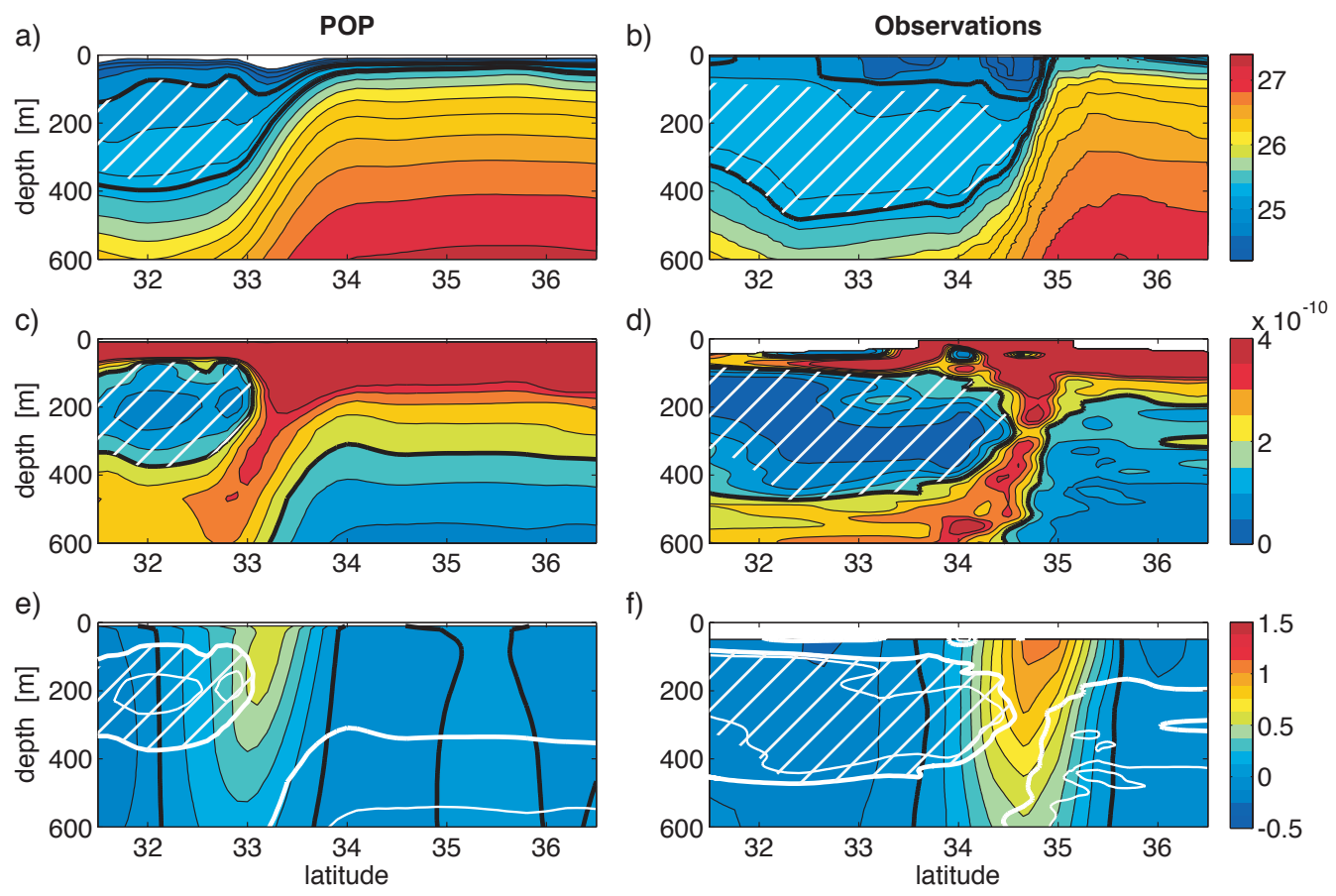

Figure 2. Section across the Kuroshio jet (a,b) potential density $\left(0.2 \mathrm{~kg} \mathrm{~m}^{-3}\right.$ intervals), (c,d) planetary potential vorticity $\left(0.5 \times 10^{-10} \mathrm{~m}^{-1} \mathrm{~s}^{-1}\right.$ intervals $)$, and (e,f) east velocity $\left(0.125 \mathrm{~m} \mathrm{~s}^{-1}\right.$ intervals) sections from the POP model averaged over the last week of May 1999 (left column) and from a CTD section collected in late May 2004 (right column) near $145^{\circ} \mathrm{E}$. Thick contours indicate the depths $\sigma_{\theta}=25.0$, $Q=2 \times 10^{-10} \mathrm{~m}^{-1} \mathrm{~s}^{-1}$, and $u=0$ respectively. Potential vorticity contours $\left(1,2 \times 10^{-10} \mathrm{~m}^{-1} \mathrm{~s}^{-1}\right)$ are also plotted in (e,f). The STMW, as defined in the text, is indicated by the hatched area.

ter the re-formation of the seasonal thermocline (generally in April), the STMW is trapped below the seasonal thermocline and the potential vorticity minimum slowly erodes. As the formation occurs in a limited area, the combined effects of advection and local erosion contribute to the decrease in the volume of mode water found at a given location.

The total STMW volume varies seasonally as well as inter-annually. During the period considered, the STMW is not in a steady state. The time series of total STMW volume in Region A (Fig. 5a) shows that the total volume of STMW is quite different from year to year. Formation occurs during the winter months (March and April), adding roughly $1 \times 10^{14} \mathrm{~m}^{3}$ of STMW each winter. A decay in volume is seen during the rest of the year. Each year is remarkably different: erosion during spring, summer, and fall 1998 is roughly equal to the formation in winter 1998. A smaller volume of STMW is formed in 1999, but enhanced erosion depletes the mode water: both its volume and area at the end of 1999 are less than half their value a year earlier. The STMW somewhat recovers in 2000, with more formation and less erosion. Such variability has been observed in the Atlantic: Kwon and Riser (2004), analyzing the last 40 years of observations in the Western North Atlantic, show that the winter volume of North Atlantic STMW can vary by as much as $50 \%$ from year to year, as is the case in the model results presented here.

The total area where STMW is found (both at the surface and subsurface, gray dashed line in Fig. 5a) does not vary much during the first year (indicating that the volume loss is almost strictly due to thinning of the layer), then decreases to less than half of its initial value in 1999, and somewhat recovers in 2000. The area over which the STMW is in contact with the atmosphere ('out- 

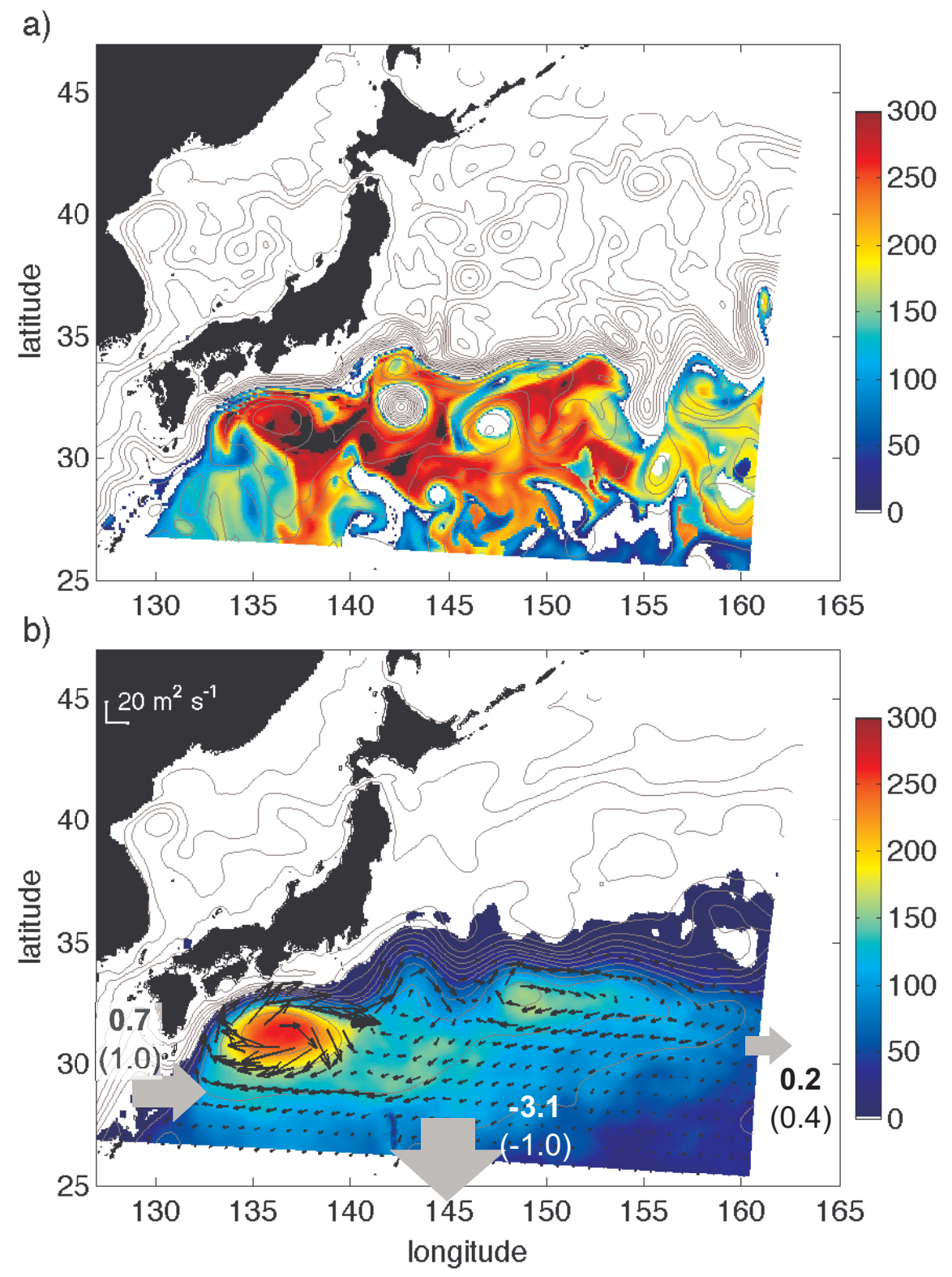

Figure 3. (a) Thickness of STMW estimated from the model on 15 Jul 1998. White denotes that no STMW is detected. Gray contours indicate the SSH on that same day (spaced by $0.1 \mathrm{~m}$ ). (b) Mean thickness of the STMW layer (shading) and mean SSH contours (gray lines) over 3 years (1998-2000) from the POP model. Averaged velocity depth-integrated over the thickness of the STMW layer is shown at selected locations (black vectors, scale on the top-left corner), and average transports of STMW through the boundaries of Region A are indicated (total transport in bold, transport of the mean in parentheses). 

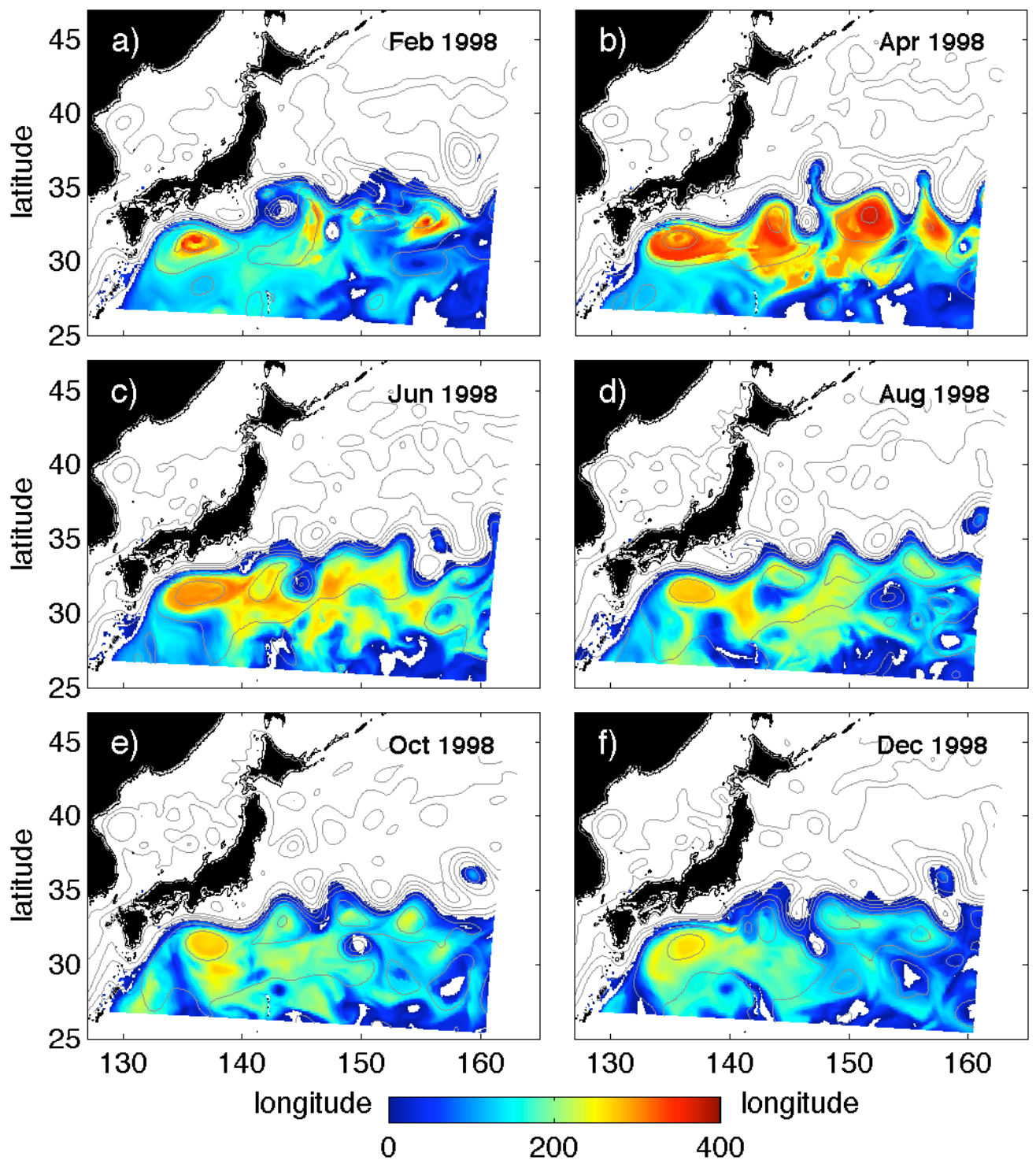

Figure 4. Monthly mean of STMW layer thickness in 1998, shown every other month. Gray contours, spaced by $0.2 \mathrm{~m}$, indicate the monthly mean $\mathrm{SSH}$. 

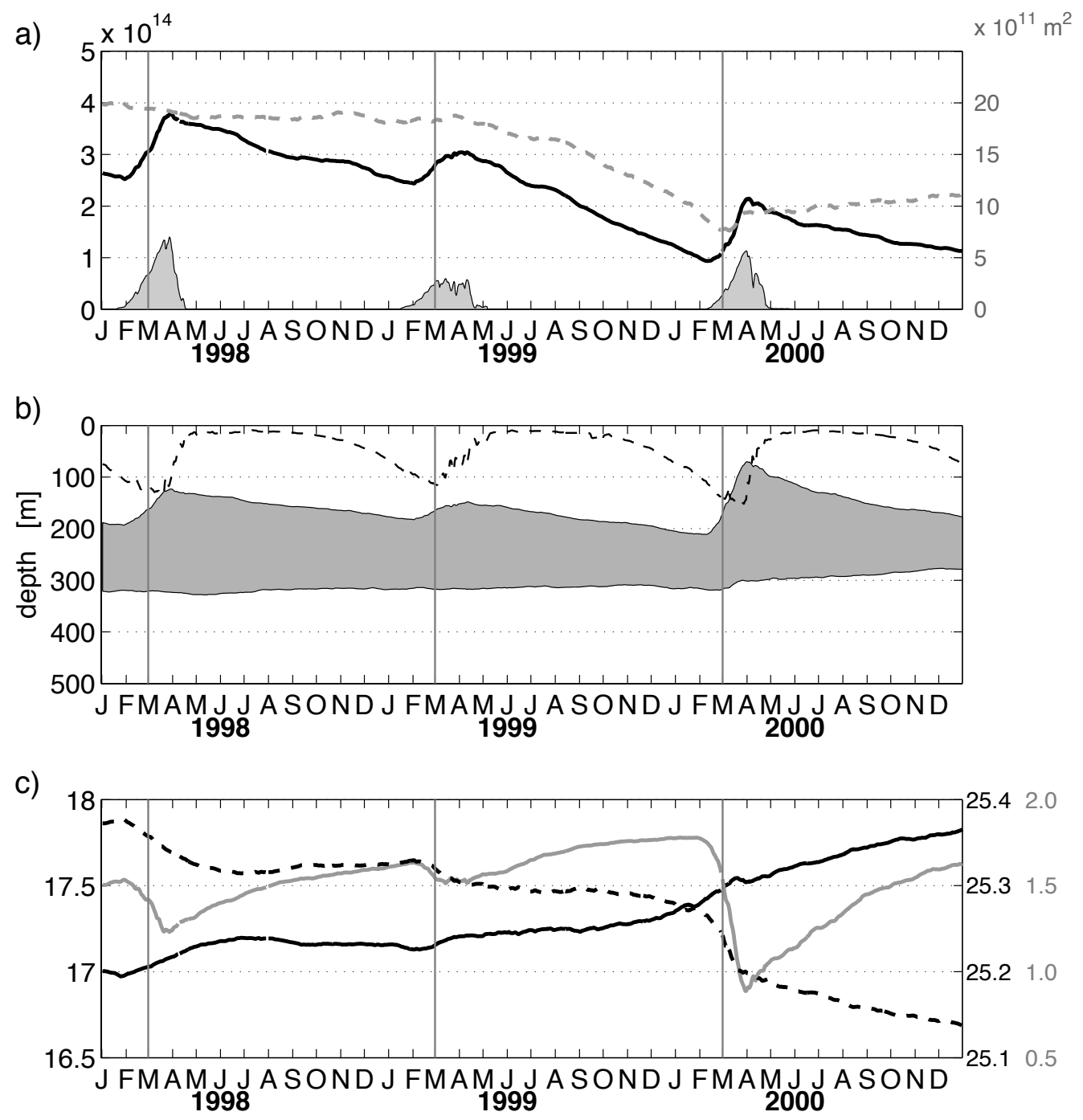

Figure 5. (a) Time series of the total volume of STMW in Region A (black, axis on the left, in $\mathrm{m}^{3}$ ), area of the STMW (gray dashed line, axis on the right), and outcrop area of STMW (gray, axis on the right, in $\mathrm{m}^{2}$ ). (b) Average depth of the STMW, (shaded), and of the mixed layer (dashed). (c) Average temperature (black, axis on the left, in ${ }^{\circ} \mathrm{C}$ ), potential vorticity (gray, axis on the right, in $\mathrm{m}^{-1} \mathrm{~s}^{-1}$ ), and potential density (dashed, axis on the right, in $\mathrm{kg} \mathrm{m}^{-3}-1000$ ) of the STMW. 
crop area', solid gray in Fig. 5a) can be thought to be a good measure of the area where mode water is formed.

The averaged depths of the bottom and top of the STMW layer in Region A are shown in Fig. 5, as well as the averaged temperature and potential vorticity of the layer. Over the 3 years when the model output is available, the temperature of the STMW is steadily increasing, by about $1^{\circ} \mathrm{C}$ over the entire period. The potential density of the STMW layer decreases accordingly by about 0.1 $\mathrm{kg} \mathrm{m}^{-3}$ year $^{-1}$ (salinity is more or less constant).

The trends seen in the properties of the STMW are likely due to "real" decadal variability rather than model drift. For example, no trend is seen in the sea-surface temperature or in the averaged properties of the upper $500 \mathrm{~m}$ of the water column. Rather, the variations of $\mathrm{T}, \mathrm{Q}$, and $\sigma_{\theta}$ of the STMW appear to be a signature of the location and quantity of STMW formed each year. Maps of the averaged temperature of the STMW in March (Fig. 6a-c) show generally warmer mode water near the Kuroshio than further south. Because STMW is formed when winter convection drives deep mixed layers, the temperature of the winter-time mixed layer has been found to correspond well to the temperature of the STMW layer (Qiu et al., 2006). The area and time of the formation of STMW can be defined as when and where the mixed layer penetrates to the depth of the STMW remaining from the year before (that is when water satisfying the mode water criteria comes in contact with the atmosphere).

In March 1998, the temperature of the mixed layer in the areas of formation is warmer than most of the STMW, suggesting that the previous years must have seen the formation of cooler SMTW. This trend continues for the 3 years we analyze here, and the warming signal can be tracked to the formation region in time. A longer time series would be necessary to determine if the cooled STMW present at the beginning of 1998 is a signature of formation in different areas, or of cooler mixed layer temperatures in 1997 and before.

\subsection{STMW budget}

A budget of the STMW includes the formation, advection by the mean circulation and eddies, and erosion (due to both explicit diapycnal interior mixing and implicit numerical mixing). In this section, we quantify the volume of STMW, defined from both the potential vorticity and den- sity criteria, in terms of formation, advection, and erosion. The forcing mechanisms for both the formation and erosion will be further investigated in the sections 4 and 5 , where a control volume defined by density alone is used.

The 3-year average of daily velocity integrated over the depth of the STMW ('total transport') is shown by the vectors in Fig. 3b for selected locations. In general, the mode water follows the circulation of the area, which can be inferred from the mean SSH contours. It is formed just south of the Kuroshio, follows the recirculation gyre, and exits the domain mostly through the southern boundary. Some STMW appears to be picked up by the Kuroshio and reenters the extracted region through the western boundary. The 3-year averages of daily transport across the boundaries of Region A are also listed (in bold, and gray bulk arrows) in Fig. 3b. Note that this quantity is about equal to the transport of STMW by the mean circulation (mean velocity integrated over the mean mode water thickness at the boundaries, termed 'transport by the mean', listed in parentheses) on the eastern, northern, and western boundaries, but is 3 times larger on the southern one.

Table 1 lists the terms of this budget for each of the 3 years of the POP simulations. The advection term is obtained by integrating the total transport through the boundaries of the Region A for the whole year. In the region we consider here, there is a net loss of STMW due to advection. The net volume exported out of Region A $\left(2.4 \times 10^{14} \mathrm{~m}^{3}\right)$ over the three years corresponds to an averaged total transport of $2.56 \mathrm{~Sv}$ (Fig. 3b). Most of this transport is associated with eddies along the southern boundary. The transport by the mean circulation is only $0.40 \mathrm{~Sv}$ out of Region A.

The volume formed each year is estimated by integrating the time series of STMW volume change minus advection over the period of time when the volume is increasing (typically early February to early April). Strictly speaking, this gives the net formation (sum of formation and erosion over that period), but we assume that the erosion is small during the formation period.

The residual is the the loss of volume that has to be added to the advection and formation terms to obtain the measured net volume change (Fig. 5). It represents the local erosion processes due to explicit vertical and lateral mixing in the interior and implicit numerical diffusion. The advection 

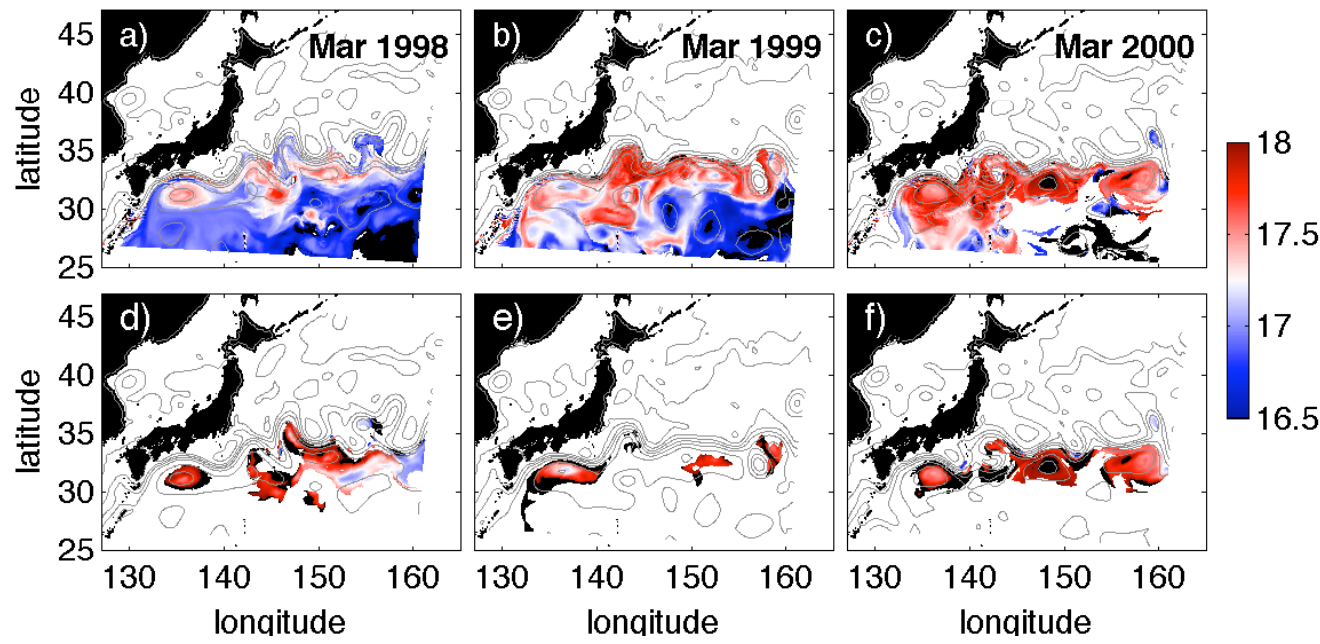

Figure 6. (a-c) Mean temperature of the STMW layer and mean SSH contours (gray lines) for March 1998, 1999, and 2000 (top row). (d-f) Mixed-layer temperature for the same month, plotted only where the STMW layer is in contact with the atmosphere.

by the mean circulation and eddies, and local erosion due to mixing processes (residual) are of the same order of magnitude, thus both appear to be important factors determining the variations in volume of STMW present in the Kuroshio Extension Region.

Not all the advection is compensated for by the formation of new mode water. Over the three years, the total STMW volume decreases by $1.5 \times 10^{14} \mathrm{~m}^{3}$. Large inter-annual variability is obvious in all terms of this rough budget; the first and last year are more or less in balance, however, less STMW is formed in 1999 while more is exported.

\section{Volume budget of the $25.0<\sigma_{\theta}<25.5$ density layer}

In this section, we investigate the forcing mechanisms in order to understand the variability in the amount of STMW formed each year in the model simulation. In order to estimate meaningful volume and potential vorticity budgets, we choose a control volume defined by $25.0<\sigma_{\theta}<$ 25.5. These two isopycnals correspond to the density range of the STMW: more than $95 \%$ of the volume defined by the sub-surface potential vorticity minimum $\left(Q<2 \times 10^{-10} \mathrm{~m}^{-1} \mathrm{~s}^{-1}\right)$ during spring, summer, and fall is contained in this density range. Given that the vertical resolution is limited to 40 levels, we allow for partial vertical cells, where we linearly interpolate the density between two levels to better estimate the depths of the isopycnals and the thickness of the density layer (thickness can thus be smaller than the thickness of one level). Transports are similarly interpolated vertically. Partial cells were not used horizontally.

As first pointed out by Walin (1982), air-sea fluxes of heat and salt modify the density of the surface water and can be used to estimate the rate of transformation of water from one density to another. The transformation rate is not the same for all density classes, and therefore water tends to accumulate or to be removed from certain density classes. Similarly, diffusive diapycnal fluxes can add or remove density to a layer. As illustrated in Fig. 7a, by volume conservation the time variation of the volume $\Delta V$ between two isopycnals $\left(\rho_{1}\right.$ and $\left.\rho_{2}\right)$ must be balanced by the net volume flux exiting the domain between the isopycnals $(\Delta \Psi)$, the formation rate of that water mass by air sea-fluxes, and by diffusive volume fluxes (Nurser et al., 1999):

$$
\begin{aligned}
\frac{\partial \Delta V}{\partial t}+\Delta \Psi= & F_{\text {atm }}\left(\rho_{1}\right)-F_{\text {atm }}\left(\rho_{2}\right) \\
& +D_{\text {diff }}\left(\rho_{1}\right)-D_{\text {diff }}\left(\rho_{2}\right) .
\end{aligned}
$$

The transformation rate $F_{\text {atm }}(\rho)$ is the volume gain due to atmospheric fluxes acting on the 


\begin{tabular}{c|c|ccc} 
& $\begin{array}{c}\text { Net volume change } \\
{\left[\times 10^{14} \mathrm{~m}^{3}\right]}\end{array}$ & $\begin{array}{c}\text { Advection } \\
{\left[\times 10^{14} \mathrm{~m}^{3}\right]}\end{array}$ & $\begin{array}{c}\text { Formation } \\
{\left[\times 10^{14} \mathrm{~m}^{3}\right]}\end{array}$ & $\begin{array}{c}\text { Residual } \\
{\left[\times 10^{14} \mathrm{~m}^{3}\right]}\end{array}$ \\
\hline 1998 & -0.1 & -0.9 & +1.3 & -0.5 \\
1999 & -1.3 & -1.2 & +0.7 & -0.8 \\
2000 & -0.1 & -0.4 & +1.1 & -0.8 \\
\hline Annual mean & -0.5 & -0.8 & +1.0 & -0.7
\end{tabular}

Table 1

Volume budget of STMW in Region A (each year and average), listing the net volume change over the whole year, volume change during the formation period (positive $d V / d t$ ), transport through the boundaries, and the residual term representing the erosion due to mixing.

outcropping surface (air-sea interface) of the $\rho$ isopycnal, and $D_{\text {diff }}$ represents the volume change driven by diffusive density flux across a given isopycnal surface. Each term is discussed in more detail below.

The averaged thickness of the $25.0<\sigma_{\theta}<25.5$ density layer is shown in Fig. 8. This water is advected by the mean circulation (more or less along the contours of SSH) and the eddies. Black vectors show the 3 -year average of daily velocity integrated over the depth of the layer (on that day) along selected sections, which are integrated over the length of each section to produce the estimate of total transport listed in bold at the bottom or right of each section. Signs are positive to the East and North. A similar calculation, but using the averaged velocity integrated over the averaged depths of the density layer, leads to estimates of the transport by the mean circulation (values in parentheses). As a large volume of STMW, which is included in this density class, is formed in the Kuroshio Extension region, there is a net transport of water out of the region. As in Section 3, the time-averaged total transport out of Region A $(2.84 \mathrm{~Sv})$ is larger than the transport of water at that density by the mean circulation (0.81 Sv out of the region), primarily because of enhanced eddy transport across the eastern and southern boundaries.

The density flux $f_{\mathrm{atm}}^{\rho}$ at the surface due to atmospheric forcing is

$$
f_{\mathrm{atm}}^{\rho}=-\frac{\alpha Q}{c_{P}}+\rho \beta S(E-P),
$$

where $\alpha$ and $\beta$ are the thermal expansion and saline contraction coefficients, $\rho$ is density at the surface, $Q$ is the air-sea heat flux (in $\mathrm{W} \mathrm{m}^{-2}$ ), $c_{P}$ is the specific heat, $S$ is salinity, $E$ and $P$ are evaporation and precipitation. For each day, integrating the density flux over the area where a given density layer outcrops in a particular region,
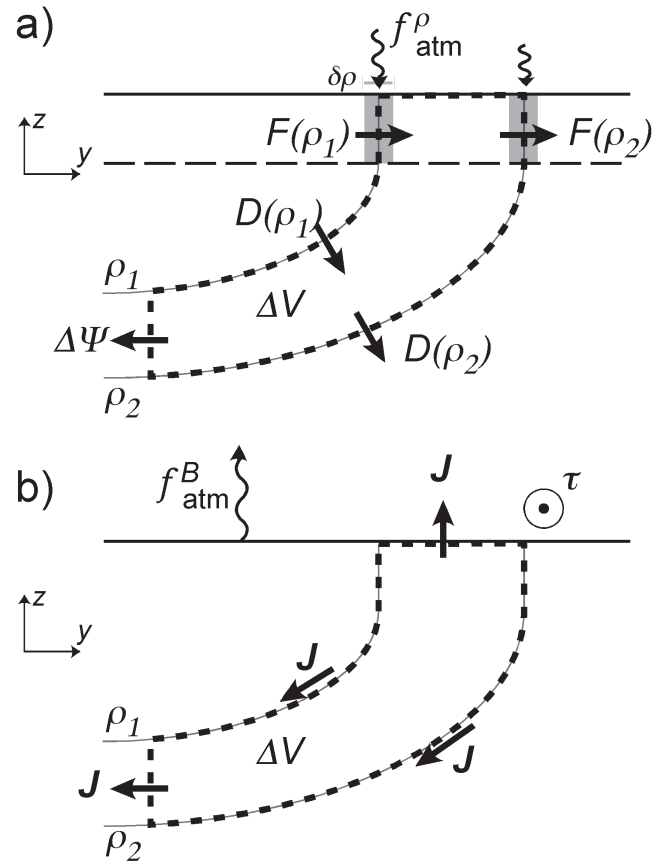

Figure 7. Schematic of the control volume between two isopycnals $\rho_{1}$ and $\rho_{2}$ (in gray) for the (a) volume and (b) potential vorticity budgets. Transformation rates $F$ due to atmospheric density fluxes $f_{a t m}$, diffusive diapycnal fluxes $D$, and advection $\Delta \Psi$ out of the control volume can lead to changes in the volume $\Delta V$. Similarly, downfront wind $\tau$ and buoyancy fluxes $f_{\mathrm{atm}}^{B}$ from the ocean to the atmosphere results in an upward PV flux $\mathbf{J}$ at the sea-surface.

the transformation rate due to air-sea fluxes of water with this particular density in the domain is obtained (Speer and Tziperman, 1992; Nurser 

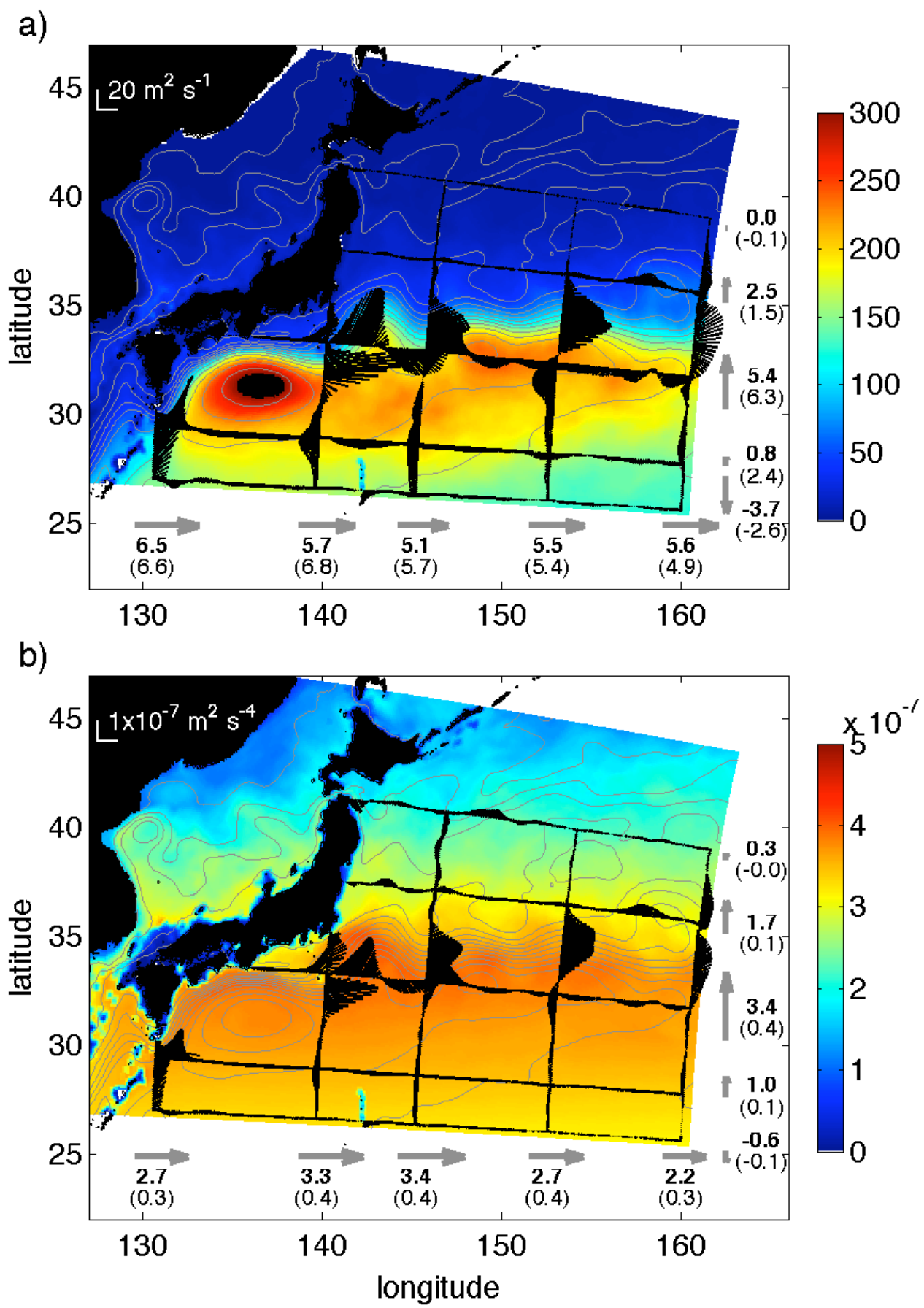

Figure 8. (a) Map of the thickness of the $25.0<\sigma_{\theta}<25.5$ density layer and mean SSH contours (gray lines) over 3 years (1998-2000) from the POP model. Depth-integrated velocity along a few sections is shown (black vectors, scale in the top-left corner) along with the integrated transports of density layer across the meridional sections at the bottom, zonal on the right (gray arrows). Total transport values (units of Sv) are listed in bold, transports by the mean in parentheses. (b) Map of depth-integrated potential vorticity and PV transport for the same density layer. Black vectors show the depth-integrated PV transport over the layer, which are integrated over length of each section to produce transport estimates (gray arrows, total transport values [units of $\mathrm{m}^{3} \mathrm{~s}^{-4}$ ] are listed in bold, transports by the mean in parentheses). 
et al., 1999; Ladd and Thompson, 2001):

$$
F_{\text {atm }}(t, \rho)=\frac{1}{\delta \rho} \int_{\text {outcrop }} f_{\text {atm }}^{\rho} d A,
$$

where the area of integration is the surface outcrop of the isopycnal $\rho \pm \delta \rho / 2$, where $\delta \rho$ is small. Different transformation rates for the two isopycnals defining a control volume imply water mass formation (or destruction) by the atmospheric fluxes. Such analysis is usually done from coastto-coast (e.g. Walin, 1982; Marshall et al., 1999), allowing to equate the difference in transformation rates to a subduction rate. Here, since we also have the $3 \mathrm{D}$ velocity field from the model, we can directly compute lateral advection and therefore perform this calculation in a region with open boundaries.

The transformation rate is plotted versus time and potential density in Fig. 9a. At any given time, the most striking feature of Fig. 9a is the extremum representing the seasonal heating and cooling in the mixed layer: very light densities are formed in the mixed layer during the summer by atmospheric warming of the surface - negative density fluxes (from April to October) and winter cooling increases the densities. At the end of winter, the water outcropping just south of the Kuroshio front corresponds to the STMW, and the second maxima occurring in winter as well in Fig. 9a around $\sigma_{\theta}=26.0$ correspond to the densities of North Pacific Central Mode Water, formed just north of the jet (Ladd and Thompson, 2001). Transformation rates are large and positive during the winter (forming denser water) and small and negative during the summer. The thermal and saline contributions to the transformation rates are separated in the annual and winter averages plotted in Fig. 9b-d. In this particular region the saline contribution is negligible.

Annual averages of the different terms of the volume budget of the density layer in Region A are listed in Table 2. The net volume change is calculated from the time series of the volume (Fig. 10). The advective component is computed by integrating the transport of water belonging to a particular density class through the side boundaries of the region. The annual water formation over the range of the density considered here due to atmospheric forcing, $\left(\overline{F_{\text {atm }}(t, 1025.0)}-\right.$ $\left.\overline{F_{\text {atm }}(t, 1025.5)}\right) \times \Delta t$, where $\bar{F}$ represents a time average of the function $F(t)$ over $\Delta t$ (in this case 1 year), is listed for each year.

Over the winter months only and in the ana- lyzed domain, the atmospheric density flux acting on the density layer leads to the formation of 1.3 , 1.1 , and $1.5 \times 10^{14} \mathrm{~m}^{3}$ for 1998,1999 , and 2000 , respectively. These values are close to the total volume of STMW formed each year $(1.3,0.8$, and $1.2 \times 10^{14} \mathrm{~m}^{3}$ respectively, Table 1$)$.

The residual term corresponds to the erosion of this density class of water by mixing processes. Note that here we cannot directly calculate mixing: the diapycnal mixing diagnostics are not available for these simulations. However, we can estimate the magnitude of explicit turbulent diapycnal mixing ("interior" mixing) by representing it in terms of a vertical velocity $(H u, 1996)$ :

$$
w_{\text {mixing }} \equiv \frac{\partial}{\partial \rho} \kappa \frac{\partial \rho}{\partial z}
$$

where $\kappa$ is the vertical eddy diffusivity. Note that the diapycnal velocities $w_{\text {mixing }}$ is not an Eulerian velocity, but rather a convenient representation of the rate at which a fluid parcel crosses isopycnals. The difference between the mixing velocities at the top and at bottom interfaces gives the rate of change in thickness of the layer due to interior diapycnal mixing (Hu, 1996; Marsh et al., 2000). By assuming $\kappa$ to be a constant, both in space and time, we can estimate $w_{\text {mixing }}$ at the top and bottom of the density layer by evaluating the first and second derivative of potential density at the appropriate depths for each day. To limit this calculation to interior mixing, we calculate the diapycnal velocity only when a given isopycnal is at least $20 \mathrm{~m}$ below the mixed layer ${ }^{3}$. Summing over all year, we find that a uniform diapycnal diffusivity $\kappa=9.1 \times 10^{-5} \mathrm{~m}^{2} \mathrm{~s}^{-1}$ is required to erode all of the residual in the volume budget by vertical mixing, on average a loss of $0.78 \times 10^{14}$ $\mathrm{m}^{3}$ per year (Table 2 ).

The value of the vertical diffusivity is an order of magnitude larger than the classical value of $\kappa=1 \times 10^{-5} \mathrm{~m}^{2} \mathrm{~s}^{-1}$ measured in open the open ocean (Gregg, 1989; Ledwell et al., 1993). The vertical diffusivity used in the POP model includes contributions from 4 different physical processes: internal waves, shear instability mixing, convective instability, and double diffusion. The representation of each of these processes in the KPP boundary layer parameterization (Large et al., 1994) leads to a spatially and temporally non-uniform vertical diffusivity of the order of $\kappa=1 \times 10^{-5} \mathrm{~m}^{2} \mathrm{~s}^{-1}$. These are not archived

\footnotetext{
${ }^{3} 20 \mathrm{~m}$ is larger than the vertical grid spacing for depths smaller than $150 \mathrm{~m}$.
} 


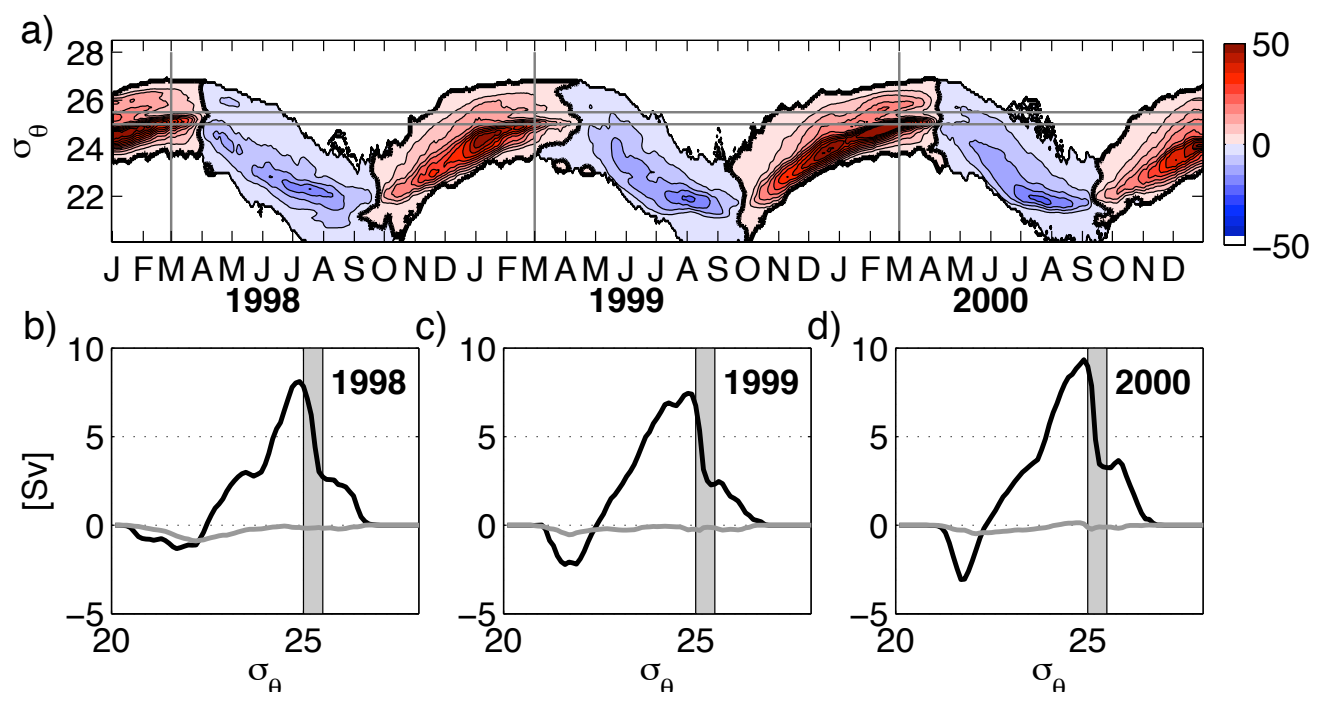

Figure 9. (a) Transformation rate $F_{a t m}(t, \rho)$, in $\mathrm{Sv}$, as a function of time and density in Region A. The STMW is found at densities between the two dashed lines. (b-d) Yearly average of transformation rates from air-sea density flux separated in the thermal (black) and haline (gray black) components. Shading indicates the densities of STMW.

\begin{tabular}{c|c|ccc} 
& $\begin{array}{c}\text { Net volume change } \\
{\left[\times 10^{14} \mathrm{~m}^{3}\right]}\end{array}$ & $\begin{array}{c}\text { Advection } \\
{\left[\times 10^{14} \mathrm{~m}^{3}\right]}\end{array}$ & $\begin{array}{c}\text { Formation } \\
{\left[\times 10^{14} \mathrm{~m}^{3}\right]}\end{array}$ & $\begin{array}{c}\text { Residual } \\
{\left[\times 10^{14} \mathrm{~m}^{3}\right]}\end{array}$ \\
\hline 1998 & -0.2 & -0.9 & +1.5 & -0.8 \\
1999 & -0.4 & -1.0 & +1.4 & -0.8 \\
2000 & +0.2 & -0.8 & +1.8 & -0.7 \\
\hline Annual mean & -0.1 & -0.9 & +1.5 & -0.8
\end{tabular}

Table 2

Volume budget of the $25.0<\sigma_{\theta}<25.5$ density layer in Region A, listing the net volume change over the whole year, the transport through the boundaries, the formation due to atmospheric forcing, and the residual term representing the erosion due to diapycnal and numerical mixing. 
and cannot be inferred from the default model outputs. In addition to this explicit vertical mixing, implicit numerical dissipation caused by the advection and time-stepping schemes could be responsible for a large part of the erosion of water in this density class (Griffies et al., 2000). Although the model erodes the STMW in a reasonable manner, future studies need to identify what processes are responsible for vertical mixing, and the sensitivity of erosion to both explicit parameterizations and implicit mixing.

Time series of the components of the volume budgets for a smaller region in the eastern part of the domain (Region B) are shown in Fig. 10b. This region is away from the coast of Japan, roughly from $145^{\circ}$ to $160^{\circ} \mathrm{E}$ and $26^{\circ}$ to $40^{\circ} \mathrm{N}$ (gray box in Fig. 1), is chosen to avoid the potential vorticity input associated with friction along the side boundary. Rate of change of volume is obtained from the daily estimates of the volume of the density layer, and the advection term by calculating daily transports across the boundaries of the region. Time series of the daily estimate of each term are smoothed over 29 days. As for the annual values quoted above, the atmospheric formation is calculated from $\left(\overline{F_{\text {atm }}(t, 1025.0)}-\right.$ $\left.\overline{F_{\text {atm }}(t, 1025.5)}\right) \times \Delta t$, where $\Delta t=29$ day. For most of the year, the advection by eddies controls the fluctuations of volume of the density layer, although is annual average is similar to the residual (Table 2). In winter, large atmospheric heat loss forms mode water. The formation during the 1999 winter is weaker.

Daily time series of the rate of change of STMW volume (going back to the $Q<2 \times 10^{-10}$ definition), wind-stress vectors, and atmospheric heat flux over the Kuroshio Extension region during the winter months emphasize the differences between the 3 years (Fig. 11). During most of February and March of both 1998 and 2000, the cold winds from the Asian continent are steady and induce large negative atmospheric heat flux. During the winter, the volume variations of STMW are directly related to strong cooling events. The wind shifts direction at the end of March and cooling stops. In 1999 however, a few wind-reversal events occur early in the season, shutting down the formation of mode water. Because of those wind events, the average atmospheric heat flux in February and March 1999 is $-95 \mathrm{~W} \mathrm{~m}^{-2}$, about half of the other two years: $173 \mathrm{~W} \mathrm{~m}^{-2}$ in 1998 and $-218 \mathrm{~W} \mathrm{~m}^{-2}$ in 2000 . The wind direction is varying on short time scales and, through its impact on air-sea heat fluxes, directly affects the formation of STMW.

\section{Potential vorticity budget}

The model also allows us to calculate the potential vorticity (PV) budget of the density layer containing the STMW. The main reason to conduct this exercise is that considerable simplification is achieved by the fact that there is no PV fluxed through the isopycnal surfaces, which eliminates the need to evaluate the internal mixing. A PV budget also allows us to infer the relative importance of diabatic (air-sea temperature differences) and frictional (ekman-driven) buoyancy fluxes at the surface, a subject of active debate for strong frontal regions (Thomas and Lee, 2005).

The potential vorticity $(\mathrm{PV})$, whose definition is expanded here to be $q=\omega_{a} \cdot \nabla b$ where $\omega_{a}=$ $f \mathbf{k}+\nabla \times \mathbf{u}$, is the absolute vorticity and $b=$ $-g \rho \rho_{0}^{-1}$ is the buoyancy ( $g$ is the gravitational acceleration, $\rho$ is the density, and $\rho_{0}$ a reference density), varies in time because of the divergence of the PV flux vector:

$$
\frac{\partial q}{\partial t}=-\nabla \cdot\left(\mathbf{J}^{\mathbf{a d v}}+\mathbf{J}^{\mathcal{D}}+\mathbf{J}^{\mathbf{F}}\right),
$$

where the three terms on the right hand side are the advective component by the flow $\mathbf{u}$, and the non-advective components of the PV flux vector due to diabatic and frictional processes, respectively.

Following the impermeability theorem of Haynes and McIntyre (1987) and as discussed by Thomas (2005), the only contributions to the volume-integrated PV over a control volume matching two outcropping isopycnals (Fig. 7b) are the PV flux out of the surface outcrop and the advection of PV through the side boundary of the region:

$$
\begin{aligned}
\frac{\partial}{\partial t} \int_{V} q d V=-\int_{\text {side }} \mathbf{J}^{a d v} \cdot \mathbf{n} d A \\
\quad-\int_{\text {outcrop }} J_{z}^{\mathcal{D}} d A-\int_{\text {outcrop }} J_{z}^{F} d A .
\end{aligned}
$$

It is important to notice that the applicability of the impermeability theorem to daily averaged fields of a numerical model with finite resolution is not expected to be exact. Sub-grid scale model closures, for example, are ignored, but it is assumed that Eq. (7) captures the dominant terms.

For the case in which atmospheric forcing leads to a loss of buoyancy at the surface of the ocean 
a)

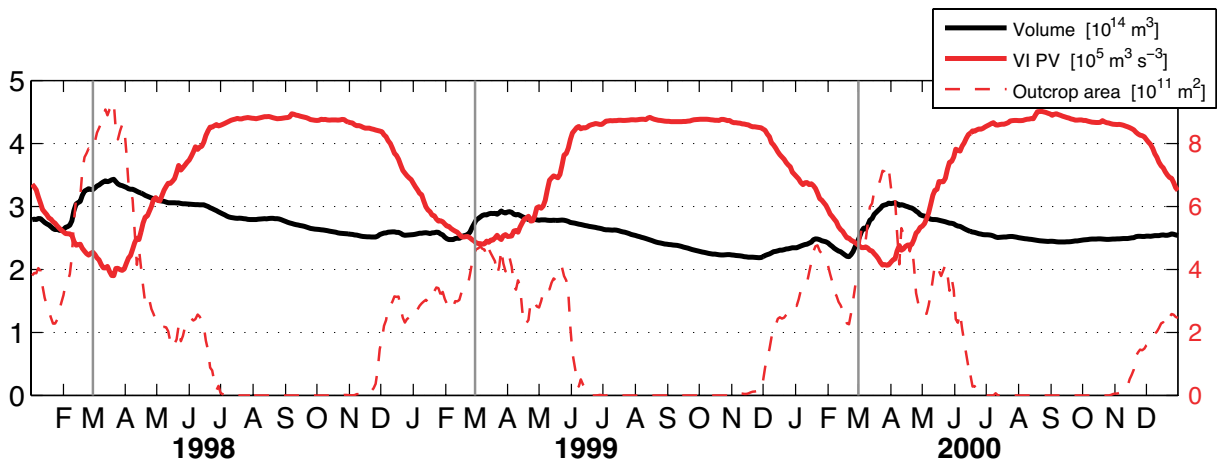

b)
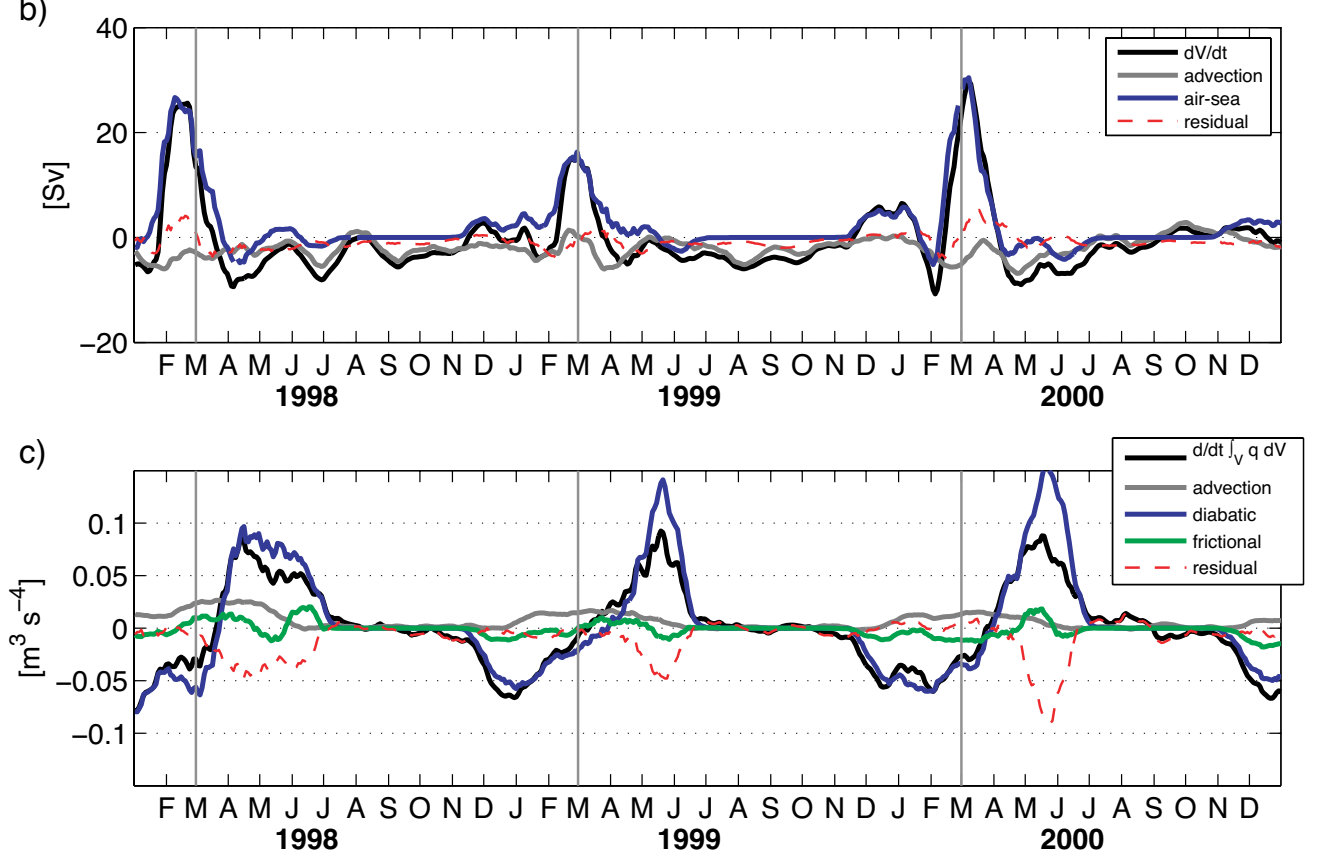

Figure 10. (a) Volume $\left(10^{14} \mathrm{~m}\right.$, black line), volume-integrated potential vorticity $\left(10^{5} \mathrm{~m}^{3} \mathrm{~s}^{-3}\right.$, red solid line), and outcrop area $\left(10^{11} \mathrm{~m}^{2}\right.$, dashed red line) of the $25.0<\sigma_{\theta}<25.5$ density layer over Region B. Axis for the red curves is on the right. (b) Volume budget, showing the rate of change of volume of the density layer (black), the advection into the region (gray), the water mass formation from the atmospheric flux (blue), and the residual (red). (c) Potential vorticity budget, showing the rate of change of volume-integrated PV (black), the advection into the region (gray), the diabatic (blue) and frictional (green) component, and the residual (red). 
a)

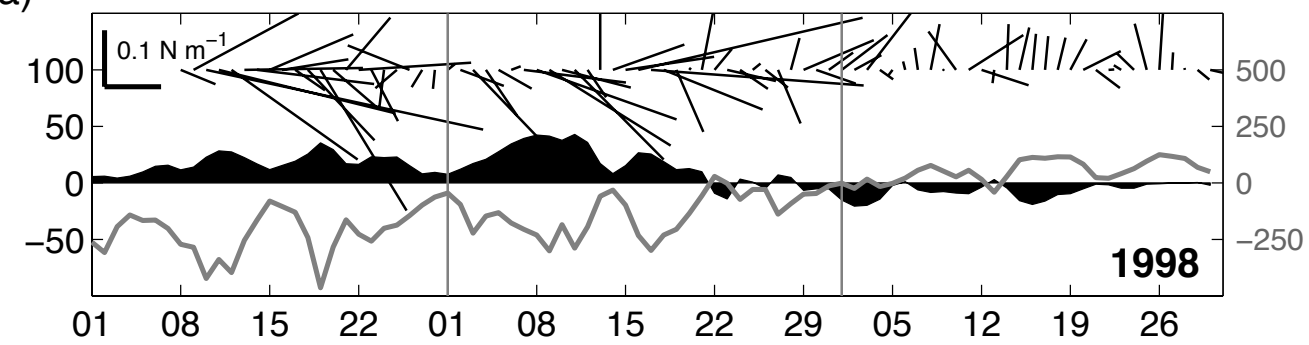

b)

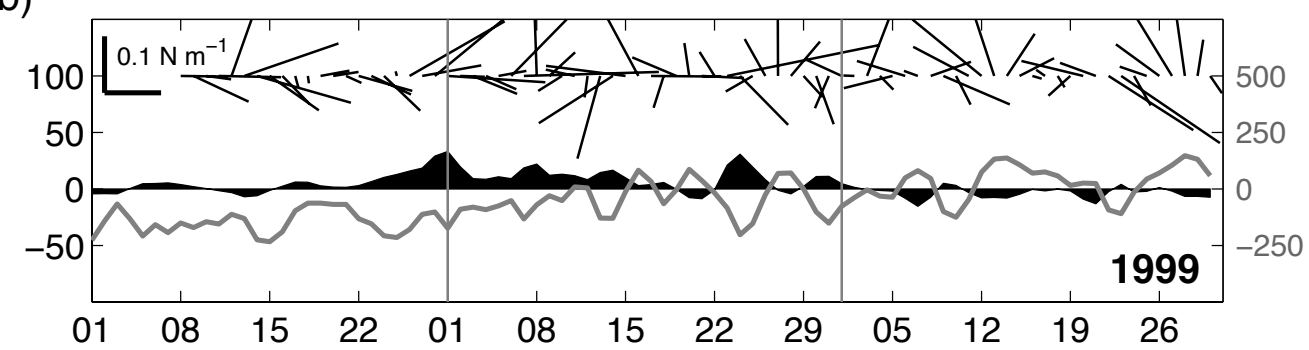

c)

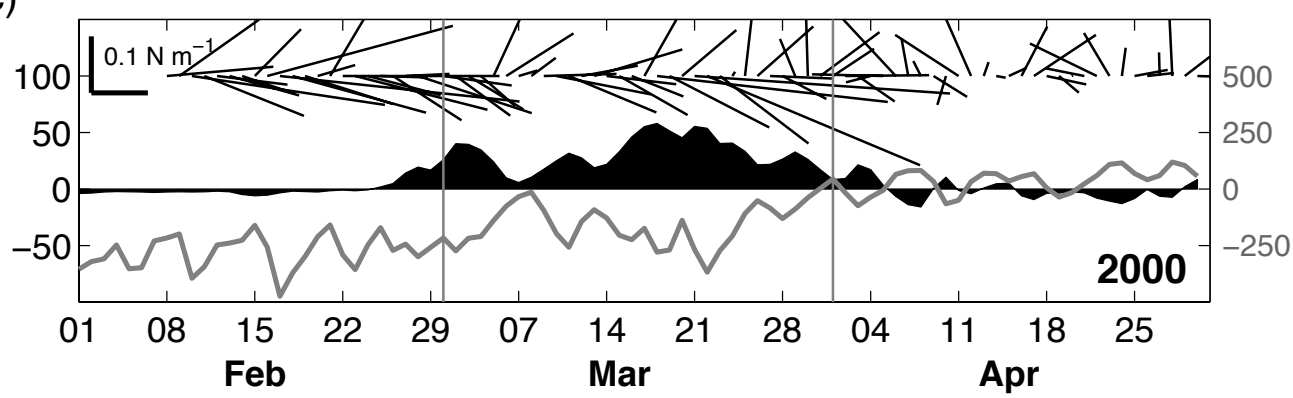

Figure 11. Daily average of STMW volume variation (black surface, in Sv [axis on the left]) and air-sea heat-flux (gray in units of $\mathrm{W} \mathrm{m}^{-2}$ [axis on the right]) averaged over Region $\mathrm{B}$ during the winter months in (a) 1998, (b) 1999, and (c) 2000. Daily-averaged wind stress vectors are also plotted. 
and thus convective instability, the atmospheric diabatic processes can be expressed as $f_{a t m}^{B} / H$, where $H$ is the mixed layer depth calculated as part of the KPP mixing scheme and based on the bulk Richardson number (see Large et al., 1994; Kara et al., 2005, for example). The assumption that the atmospheric buoyancy flux is distributed over the entire mixed layer might not be valid for the case of a buoyancy gain (heating). A smaller scale might be more appropriate, but here it is assumed that this scaling is valid for both signs of $f_{\text {atm }}^{B}$. Therefore the vertical component of the diabatic PV buoyancy flux is (Thomas, 2005)

$$
J_{z}^{\mathcal{D}} \approx-(f+\zeta) \frac{f_{a t m}^{B}}{H},
$$

where $\zeta=\partial_{x} v-\partial_{y} u$ is the vertical component of the relative vorticity.

For the frictional non-conservative forces, we consider a wind stress of strength $\tau_{0}$ exerting a force over the turbulent boundary layer of thickness $\delta_{e}=0.4 u^{*} f^{-1}$, where $u^{*}=\sqrt{\tau_{0} f^{-1}}$ is the frictional velocity (Wimbush and Munk 1970):

$$
\mathbf{F}=\frac{1}{\rho_{0}} \frac{\partial \tau}{\partial z} \approx \frac{1}{\delta_{e} \rho_{0}} \tau .
$$

Then, following Thomas (2005),

$$
J_{z}^{F} \equiv \nabla b \times \mathbf{F} \approx-\frac{f}{\delta_{e}} \mathbf{M}_{\mathbf{e}} \cdot \nabla_{H} b,
$$

where the Ekman transport $\mathbf{M}_{\mathbf{e}}$ is

$$
\mathbf{M}_{\mathbf{e}}=\frac{1}{\rho_{0} f}\left(\tau_{y},-\tau_{x}\right)
$$

An eastward cold air outbreak from land masses blowing over frontal regions with warm water on the South and cold water in the North (such as for western boundary currents) produces a negative buoyancy flux (destabilizing). As pointed by Thomas and Lee (2005), locally the buoyancy flux generated by winds acting over fronts can be of the same order of magnitude, and even larger, than the atmospheric buoyancy fluxes. In order to directly compare the frictional effects to the more familiar diabatic atmospheric processes (airsea heat flux), we can define an equivalent winddriven heat flux from the frictional PV flux:

$$
F_{\text {wind }}^{Q} \equiv-\frac{\rho c_{P}}{\alpha g} \mathbf{M}_{\mathbf{e}} \cdot \nabla_{H} b .
$$

Maps of 1-week averages taken in the middle of March 1998 of the air-sea heat flux and equivalent wind-driven heat flux are shown in Fig. 12.
STMW is formed just south of the each crests of the meandering Kuroshio, particularly where large air-sea heat flux generated a deep mixed layer. This formation is obvious in the monthly averages presented in Fig. 4a,b.

As in the previous section, the terms contributing to Eq. 7 for a control volume defined by the isopycnals $25.0<\sigma_{\theta}<25.5$ are calculated from the outputs of the model in the KE region (Region B, gray box of Fig. 1). Time series of each term, smoothed over 29 days, are presented in Fig. 10c. To a first order, the rate of change in the volume integrated PV is controlled by the diabatic processes acting on the outcropping surface. Averaged over such a large area and smoothed in time, wind-driven frictional PV fluxes are small, although they contribute to decrease of the stratification in the winter. A possible explanation is that the frictional PV fluxes are large and of both signs independently of the wind direction, while diabatic PV fluxes are only large and negative when the cold winds come from the asian continent. There is a net advection gain of PV in the region (averaging $+0.29 \times 10^{5} \mathrm{~m}^{3} \mathrm{~s}^{-4}$ per year), indicating that even if on average more water in this density class leaves the region (Fig. 10b), the $\mathrm{PV}$ of the water going out is greatly reduced relative to that of the water advected in. Again, the potential vorticity transport is dominated by eddy transport.

During the months with large positive atmospheric air-sea flux, the estimate of diabatic PV flux appears to be too large relative to the observed variation of depth-integrated PV (Fig. 10 c, from May and June, in particular). The increase of depth-integrated PV during this time is due to re-stratification of the water column; in and to the north of the Kuroshio, the density layer is confined to a small mixed layer or a thin layer in the seasonal thermocline. For example, the median model mixed layer depth in May 2000 in the area where $J_{z}^{\mathcal{D}}$ is non-zero is less than $15 \mathrm{~m}$. For such small values of the mixed layer depth, the calculation of PV flux from the atmospheric buoyancy flux (Eq. 8) might be imprecise. In addition, it is possible that the resolution of the model does not capture all the potential vorticity of the density layer in a highly stratified thermocline near the surface.

Averaged over large area, the PV fluxes associated with cooling from the atmosphere (diabatic) dominates over the wind-driven (frictional) fluxes. The frictional wind-driven PV flux might 


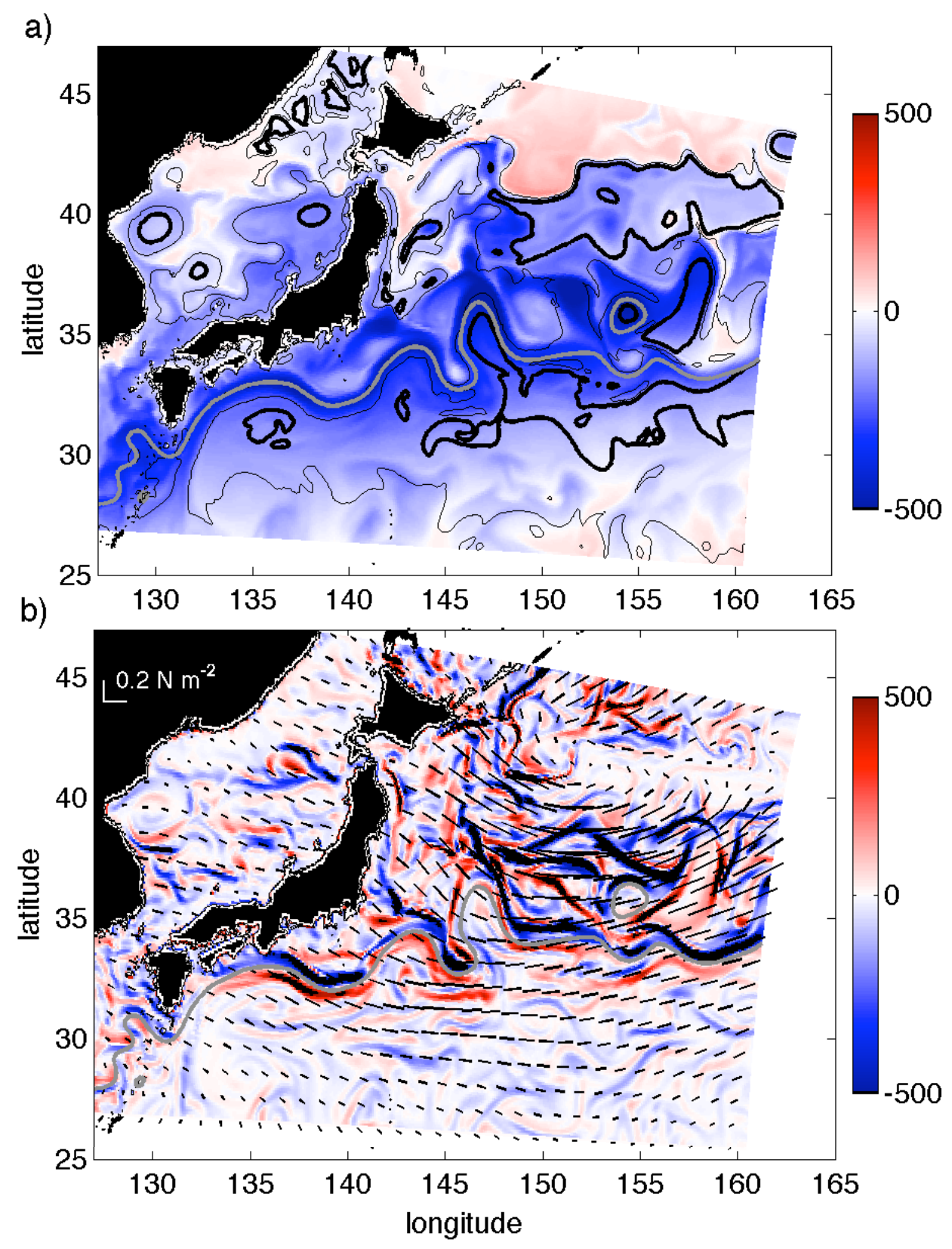

Figure 12. One-week averages in the middle of March 1998 of (a) air-sea heat flux (in units of $\mathrm{W} \mathrm{m}^{-2}$ ) and contours of mixed layer depth (100-m contour in thin, 200-m in thick black lines) and (b) frictional PV flux expressed as a equivalent heat-flux (in units of $\mathrm{W} \mathrm{m}^{-2}$ ) with wind stress vectors (scale on the top-left corner). Thick gray line in indicates the SSH contour corresponding to the middle of the Kuroshio. 
be important at smaller spatial scales (e.g. local stability of fronts), but does not appear to play a major role in the STMW formation.

\section{Conclusions}

In this study, the output of a high-resolution numerical model is analyzed on a regional scale to determine the dominant factors contributing to the formation and dispersion of STMW. The model reproduces well the dynamics of the Kuroshio Extension region and the properties of the Kuroshio Current. To correctly simulate the formation of STMW, the model needs to both be forced correctly and have a similar state of the jet and mesoscale activity.

The position of the jet and mesoscale variability are responsible for the thickness and area of the STMW layer to vary on a fast time scale. On any given day, the spatial distribution of the mode water layer is very inhomogeneous and different than the classic picture of a smooth distribution over the north-western part of the subtropical gyre. In particular, anticyclonic eddies and recirculations contains thick STMW, maybe because they keep water in regions of high heat loss as opposed to flowing eastward in the Kuroshio, and therefore favor the formation of deep winter mixed layers and STMW.

Formation of STMW is shown to be a process that is highly variable in both space and time (Fig. 6). The strength of atmospheric air-sea heat fluxes appear to be the dominant factor controlling the volume of STMW formed for a given year, but the formation in the model is dominated by episodic events with time scales of days that can be directly related to wind storms coming from the North-West (Fig. 11). The volume variation of STMW is almost a mirror image of the air-sea heat flux time series. Because the formation of mode water occurs in relatively small regions (anticyclones of the meandering jet) and during a short time period (few events spread over less than 2 months), the position of the Kuroshio and of eddies can also play an important role by blocking certain areas. For example, the cyclonic eddy located at $33^{\circ} \mathrm{N}, 158^{\circ} \mathrm{E}$ in March 1999 (Fig. 6b,e) appears to block the formation in an area that sees deep mixed layers and renewal of mode water in both 1998 and 2000. Preconditioning (building up deep mixed layer in the earlier part of the winter) is without a doubt also an important contributor in where and how much
STMW is formed, and further studies are warranted to quantify its importance relative to the winter storms of February and March.

Integrated over a large (regional) area, the cooling from the atmosphere dominates over the wind-driven potential vorticity fluxes (Thomas and Lee, 2005). As the magnitude of wind-driven (frictional) PV flux during a wind event is of the same order or even larger than the diabatic PV fluxes, the Ekman transport associated with the wind blowing down-front might have an important effect on the potential vorticity budget at smaller spatial scales (e.g. local stability of fronts), but it does not appear to play a major role in the STMW formation.

Advection, which is dominated by eddy transport south of the Kuroshio, is a major factor redistributing the STMW in the gyre. Over the Kuroshio Extension region, the volume decrease of STMW due to local erosion (interior and numerical mixing) is of the same order of magnitude as the advection. In contrast to the assumption of Qiu et al. (2006), our analysis of the POP model shows that one cannot ignore advection in budgets of STMW. Erosion of STMW happens over a large region of the gyre, not only locally.

On a larger scale, all of the STMW that is formed has to be ultimately eroded by mixing (in a steady state). In the numerical model, a large vertical diffusivity (relative to observed open ocean values) is required to explain the erosion of the water with a density corresponding to the STMW. It is not clear if this is due to enhanced values from the explicit parameterization of physical processes or implicit numerical diffusion. One needs to quantify where and how this mixing occurs in the model. However, particularly for global high-resolution models, this is difficult from the archived output files. Specific diagnostic fields for quantifying the diapycnal mixing would be needed for such case studies. In the real ocean, processes that can enhance dissipation, such as internal wave breaking and trapping by eddies or mean currents, might play an important role in eroding STMW. To understand the processes governing the erosion of STMW, it would be important to calculate the magnitude of the mixing and where it occurs, both in numerical models and in the ocean. 


\section{Acknowledgements}

We are grateful to the Department of Defense High Performance Computing Centers: the Naval Oceanographic Office and the Maui High Performance Computing Center (MHPCC). We would like to thank Leif Thomas, Nelson Hogg, and Kurt Polzin for helpful discussions, and two anonymous reviewers for their constructive comments. The model runs were supported by the National Science Foundation and the Office of Naval Research. LR acknowledges support of the Doherty Foundation. This work was sponsored by the National Science Foundation OCE-0220161 (SJ) and OCE-0221781/0549225 (JM), the Office of Naval Research (JM, MM), Department of Energy /CCPP (MM), and the Office of Science (BER), U.S. Department of Energy, Grant No. DE-FG02-05ER64119 (JM).

\section{References}

Bates, N., A. Pequignet, R. Johnson, and N. Gruber, A short-term sink for atmospheric CO2 in subtropical mode water of the North Atlantic Ocean., Nature, 420, 489-493, 2002.

Bingham, F., Formation and spreading of subtropical mode water in the North Pacific., $J$. Geophys. Res., 97(C7), 11,177-11,189, 1992.

Doney, S., J. Kleypas, J. Sarmiento, and P. Falkowski, The US JGOFS synthesis and modeling project - An introduction., Deep-Sea Res. Part II, 49, 1-20, 2002.

Ducet, N., P. L. Traon, and G. Reverdin, Global high-resolution mapping of ocean circulation from TOPEX/Poseidon and ERS-1 and -2., $J$. Geophys. Res., 105(C8), 19,477-19,498, 2000.

Dukowicz, J., and R. Smith, Implicit freesurface method for the Bryan-Cox-Semtner ocean model., J. Geophys. Res., 99 (C4), 79918014, 1994.

Dukowicz, J., R. Smith, and R. Malone, A reformulation and implementation of the BryanCox-Semtner ocean model on the connection machine., J. Atmos. Oceanic Technol., 10, 195208, 1993.

Fox, D., W. Teague, C. Barron, M. Carnes, and C. Lee, The Modular Ocean Data Assimilation System (MODAS)., J. Atmos. Oceanic Technol., 19(2), 240-252, 2002.
Gill, A., Atmosphere-Ocean Dynamics, 662 pp., Academic Press, 1982.

Gregg, M. C., Scaling turbulent dissipation in the thermocline., J. Geophys. Res., 94, 9686-9698, 1989.

Griffies, S. M., R. C. Pacanowski, and R. W. Hallberg, Spurious diapycnal mixing associated with advection in a z-coordinate ocean model., Monthly Weather Rev., 128, 538-564, 2000.

Haynes, P., and M. McIntyre, On the evolution of vorticity and potential vorticity in the presence of diabatic heating and frictional or other forces., J. Atmos. Sci., 44, 828-841, 1987.

$\mathrm{Hu}$, D., The computation of diapycnal diffusive and advective scalar fluxes in multilayer isopycnic-coordinate ocean models., Mon. Wea. Rev., 124, 1834-1851, 1996.

Joyce, T., C. Deser, and M. Spall, The relation between decadal variability of subtropical mode water and the North Atlantic Oscillation., J. Clim., 13, 2550-2569, 2000.

Kalnay, E., et al., The NCEP/NCAR 40-year reanalysis project., Bull. Amer. Meteor. Soc., 77, 437-471, 1996.

Kara, A., A. Wallcraft, and H. Hurlburt, How does solar attenuation depth affect the ocean mixed layer? Water turbidity and atmospheric forcing impacts on the simulation of seasonal mixed layer variability in the Turbid Black Sea ., J Climate, 18, 389-409, 2005.

Kwon, Y.-O., and S. Riser, North Atlantic Subtropical Mode Water: A history of oceanatmosphere interaction 1961 - 2000., Geophys. Res. Lett., 31, doi:10.1029/2004GL021116, 2004.

Ladd, C., and L. Thompson, Water mass formation in a isopycnal model of the North Pacific., J. Phys. Oceanogr., 31, 1517-1537, 2001.

Large, W., J. McWilliams, and S. Doney, Oceanic vertical mixing: A review and a model with a nonlocal boundary layer parameterization., Rev. Geophys., 32, 363-403, 1994.

Large, W., G. Danabasoglu, S. Doney, and J. McWilliams, Sensitivity to surface forcing and boundary layer mixing in a global ocean model: Annual-mean climatology., J. Phys. Oceanogr., 27, 2418-2447, 1997. 
Ledwell, J. R., A. J. Watson, and C. S. Law, Evidence of slow mixing across the pycnocline from an open-oean tracer release experiment., $\mathrm{Na}$ ture, 364, 701-703, 1993.

Maltrud, M., and J. McClean, An eddy resolving global 1/10 degrees ocean simulation, Ocean Modeling, 8, 31-54, 2005.

Marsh, R., A. Nurser, A. Megann, and A. New, Water mass transformation in the Southern Ocean of a global isopycnal coordinate GCM, J. Phys. Oceanogr., 30, 1013-1045, 2000.

Marshall, J., D. Jamous, and J. Nilsson, Reconciling thermodynamic and dynamic methods of computation of water-mass transformation rates, Deep-Sea Res., 46, 545-572, 1999.

Masuzawa, J., Subtropical mode water, Deep-Sea Res., 16, 463-472, 1969.

McClean, J., M. Maltrud, , and F. Bryan, Measures of the fidelity of eddying ocean models, Oceanography, 19, 104-117, 2006.

Nurser, A., R. Marsh, and R. Williams, Diagnosing water mass formation from airsea fluxes and surface mixing., J. Phys. Oceanogr., 29, 14681487, 1999.

Qiu, B., and S. Chen, Variability of the Kuroshio Extension jet, recirculation gyre and mesoscale eddies on decadal timescales., $J$. Phys. Oceanogr., 35, 2090-2103, 2005.

Qiu, B., and S. Chen, Decadal variability in the formation of the North Pacific Subtropical Mode Water: Oceanic- vs. atmosphericcontrol., J. Phys. Oceanogr., in press, 2006.

Qiu, B., P. Hacker, S. Chen, K. Donahue, D. Watts, H. Mitsudera, N. Hogg, and S. Jayne, Observations of the Subtropical Mode Water evolution from the Kuroshio Extension System Study (KESS)., J. Phys. Oceanogr., 36, 457473, 2006.

Rio, M., and F. Hernandez, A mean dynamic topography computed over the world ocean from altimetry, in situ measurements, and a geoid model., J. Geophys. Res., 109, doi:C12032, 2004.

Rossow, W., and R. Schiffer, ISCCP cloud data products., Bull. Amer. Meteor. Soc., 72, 2-20, 1991.
Smith, R., J. Dukowicz, and R. Malone, Parallel ocean general-circulation modeling., Physica D, 60, 38-61, 1992.

Speer, K., and E. Tziperman, Rates of water mass formation in the North Atlantic Ocean., J. Phys. Oceanogr., 22, 93-104, 1992.

Suga, T., and K. Hanawa, The subtropical mode water circulation in the North Pacific., J. Phys. Oceanogr., 25, 958-970, 1995a.

Suga, T., and K. Hanawa, Interannual variation of North Pacific subtropical mode water in the $137^{\circ}$ E section, J. Phys. Oceanogr., 25, 10121017, 1995b.

Thomas, L., Destruction of potential vorticity by winds, J. Phys. Oceanogr., 35, 2457-2466, 2005.

Thomas, L., and C. Lee, Intensification of ocean fronts by down-front winds, J. Phys. Oceanogr., 35, 1086-1102, 2005.

Walin, G., On the relation between sea-surface heat flow and thermal circulation in the ocean, Tellus, 34, 187-195, 1982.

Worthington, L., The $18^{\circ}$ water in the Sargaso Sea, Deep-Sea Res., 5, 297-305, 1959.

Xie, P., and P. Arkin, Global precipitation: A 17year monthly analysis based on gauge observations, satellite estimates, and numerical model outputs., Bull. Amer. Meteor. Soc., 78, 25392558, 1997. 